\title{
EL LIBERALSOCIALISMO PARA BOBBIO Y PARA NOSOTROS
}

\author{
Michelangelo Bovero \\ Universidad de Turín
}

RESUMEN. Partiendo de las ideas sobre el liberalsocialismo en el pensamiento de Norberto BoBbio y hallando en el ámbito del constitucionalismo el terreno propicio, no ya para un compromiso, sino para una forma de reconciliación entre la tradición liberal y la socialista, el autor propone una caracterización del liberalsocialismo articulada en dos niveles: en un "liberalsocialismo mínimo" (o liberalsocialismo para la democracia), entendido como un "mínimo indispensable para la democracia", y en un "liberalsocialismo máximo" (o liberalsocialismo en la democracia), esto es, "la conjugación entre la máxima libertad individual y la máxima justicia social históricamente posibles en cada ocasión".

Palabras claves: Norberto Bobbio, liberalsocialismo, democracia.

ABSTRACT. Taking Norberto Bobbio's ideas on liberal-socialism as a starting point, and finding in the scope of constitutionalism the breeding ground for a means of reconciliation between the liberal and the socialist traditions, rather than a compromise, the author puts forward a characterization of liberal-socialism made up of two levels: of a "minimal liberal-socialism" (or liberal-socialism for democracy), understood as "what is strictly necessary for democracy", and of a "maximum liberal-socialism" (or liberal-socialism in democracy), that is to say, "the marrying of the maximum individual freedom and the maximum social justice historically possible on each occasion".

Keywords: Norberto Bobbio, liberal-socialism, democracy. 
as reflexiones sobre el liberalsocialismo, o sobre el socialismo liberal, constituyen en mi opinión el auténtico núcleo del pensamiento de BoBBio como "filósofo militante".

Es sabido que BOBBIO usa a menudo indistintamente «liberalsocialismo» y «socialismo liberal»; es más, en ocasiones las pone al lado de otras fórmulas como «liberalismo social»o «socialista». Más allá de las cuestiones debatidas por los historiadores profesionales, para BOBBIO todas estas expresiones plantean el mismo problema esencial, conceptual: el de la compatibilidad entre liberalismo y socialismo, entendidos como visiones generales del mundo político. A pesar de la variedad infinita y litigiosa de las interpretaciones que se han dado de uno y otro, liberalismo y socialismo casi siempre han sido considerados antitéticos, como los términos de la verdadera e insuperable contraposición de la modernidad política, y por consiguiente destinados a entrar en conflicto: un conflicto, precisa BовBIO $^{1}$, que puede considerarse mortal si se sostiene, como por ejemplo se ha sostenido sobre todo desde la perspectiva marxista, que la victoria de uno no puede sino coincidir con la supresión del otro; pero también puede considerarse pacífico si se reconoce, como se ha reconocido en las democracias consolidadas y en las inauguradas por las constituciones de la posguerra, la posibilidad de la alternancia entre orientaciones políticas opuestas inspiradas en aquéllos. Sin embargo, como excepción en la historia del pensamiento político, hay una tradición rastreable a partir de la mitad del siglo XIX en la cultura anglosajona, que no ha conocido, al contrario de lo que ha sucedido frecuentemente en la cultura política europea continental, y sobre todo en la del movimiento obrero, una hegemonía del marxismo (aun en la variedad de los muchos marxismos, a su vez infinitos y litigiosos). Pero más que una auténtica y propia tradición - lo he sostenido en otra parte ${ }^{2}$ - quizás es representable como una sucesión de ilustres figuras intelectuales, que van desde John Stuart MiLl a HobHOuSE y a RuSSELl: estos personajes, aun diversos entre ellos, pueden ser considerados como precursores o pioneros del intento de conjugar, con resultados más o menos felices de síntesis teórica, los principios fundamentales del liberalismo y del socialismo: la garantía de una amplia esfera de libertad individual y la promoción de la igualdad y la justicia social. Entre los rasgos genéricamente comunes de sus elaboraciones, aquello en lo que se puede identificar la condición de posibilidad del propio intento mismo de una síntesis liberalsocialista — como subraya BOBBIO, retomando una tesis de Karl POLANYI ${ }^{3}$ - concierne a la "metafísica influyente" por ellos compartida (con mayor o menor coherencia y lucidez): una visión antideterminista de la historia y una concepción anticolectivista de la sociedad. Es sobre estas bases y en este horizonte ideal donde se podía y se puede plantear el problema de la mediación, bien sea político-programática bien sea teórico-filosófica, entre

\footnotetext{
${ }^{1}$ En el artículo «Socialismo liberale» de 1989, ahora en BoBBIo, N., 2005: Cinquant'anni e non bastano, Siena.

${ }^{2}$ En el ensayo «Liberalismo, socialismo, democrazia. Definizioni minime e relazioni possibili», en BovERO, M.; Mura, V., y SbARBERI, F. (comps.), 1994: I dilemmi del liberalsocialismo, Roma: La Nuova Italia Scientifica, pp. 303-320.

3 Siempre en «Socialismo liberale», 1989.
} 
los valores más altos que inspiran las dos ideologías contrapuestas, es decir, entre la libertad y la igualdad.

Pero más que de mediación, integración o síntesis, BOBBIo ha preferido siempre hablar de compromiso: «porque —explica - estos dos valores, tomados en su forma absoluta y entendidos como valores últimos, son incompatibles en el sentido de que ninguna sociedad en el mundo podrá ser al mismo tiempo totalmente libre y totalmente igualitaria, es decir, compuesta por individuos completamente libres y completamente iguales entre sí» ${ }^{4}$. La idea de compromiso, más que de integración, se revela en efecto más adecuada si se consideran por ejemplo ciertos aspectos del programa del Partito d'Azione (el partido nacido de la Resistenza contra el nazifascismo, y desaparecido poco después del inicio de la época republicana, que heredó el espíritu del movimiento liberalsocialista y en el cual BOBBIO tuvo su única experiencia política militante): desde el punto de vista económico, sobre todo, la mediación entre ideas liberales e ideas socialistas se resolvió mediante una especie de división del espacio disponible, es decir, en la propuesta de la economía a dos sectores. En cambio, me parece percibir algo más que un compromiso, y diría que es incluso una forma de integración, en el modo en el que el mismo BoBBIO considera el problema en su dimensión más propiamente político-institucional, o mejor, constitucional: aludo naturalmente al connubio entre derechos de libertad y derechos sociales. En la historia del socialismo liberal o liberalsocialismo italiano, la elaboración de la doctrina de los derechos fundamentales en la dirección de este connubio fue sobre todo obra, y mérito eminente, de Piero Calamandrei. BobBio no pierde ocasión de subrayarlo. En el amplio ensayo introductorio de 1946 a la reedición del libro de Francesco RUFFINI sobre los Derechos de libertad (que había sido originalmente publicado veinte años antes por Piero GOBETTI), CALAMANDREI argumentaba que el reconocimiento y la protección constitucional de los derechos sociales debía considerarse la necesaria garantía de los mismos derechos de libertad, en cuanto condición indispensable para su efectivo disfrute y ejercicio, en otro caso restringido al privilegio de pocos; y en tal reconocimiento invitaba a ver el «injerto» de la tradición socialista en la tradición liberal. Citaba la emblemática afirmación de RosseLLI, «socialismo es liberalismo en acción», señalando en ella: «el significado de ciertas fórmulas programáticas — socialismo liberal, justicia y libertad, liberalsocialismo - en las que se ha tratado de expresar en síntesis no tanto una especie de equilibrio inestable entre dos aspiraciones heterogéneas y contrapuestas, libertad individual y justicia social, cuanto la superación de esta contraposición y el reconocimiento de que la justicia social es condición de la libertad individual»s.

Ésta le parece a BOBBIo la verdadera médula del liberalsocialismo (o socialismo liberal si se prefiere) como filosofía política. A partir de aquí se puede reformular el problema conceptual: compromiso o integración, ¿entre qué elementos? ¿Qué liberalismo y qué socialismo? ¿Qué almas de las dos grandes corrientes ideológicas his-

\footnotetext{
${ }^{4}$ Cfr. Bobito, 2005: p. 228.

5 CAlamandRei, P., 1946: L'avvenire dei diritti di libertà, Introducción a la segunda edición de RufFini, F., Diritti di libertà, Firenze: La Nuova Italia editrice, reimpr. anastatica 1975, p. XXXI: la cursiva es de CALAMANDREI. Subrayo que en este célebre paso, varias veces recordado por BOBBIO, los dos nombres, socialismo liberal y liberalsocialismo, vienen equiparados.
} 
tóricamente enfrentadas podían y pueden concebirse como compatibles y conciliables en el proyecto liberalsocialista? Es cierto que el liberalismo liberista del Estado mínimo, o ultramínimo, que eleva las reglas del mercado —o peor, el mercado desregulado, sin vínculos ni límites, la libertad salvaje del bomo oeconomicus - a principio supremo de la organización social era y es incompatible con el socialismo, con cualquier socialismo, sea la que sea la interpretación que se quiera sostener de él; se entienda como se quiera, el socialismo es inseparable de la aspiración de instaurar la justicia como igualdad en la satisfacción de las necesidades esenciales y de protegerla contra la mercantilización integral de la vida social. En el otro extremo, el socialismo colectivista y burocrático del Estado máximo, o del Estado total, que regula todo desde arriba en función de una presunta, y en realidad ficticia, igualación de las posiciones sociales, hasta sofocar toda iniciativa individual y la atmósfera misma de la libertad, no podía y no puede concebirse como compatible con el liberalismo como quiera que se interprete; su mismo nombre resultaría vaciado de sentido al privársele de la referencia esencial al principio de autodeterminación individual. La única vía era y es, mutatis mutandis, la de la conjugación de los derechos de libertad de la tradición liberal y los derechos sociales que se podían considerar resultado de las reivindicaciones y luchas socialistas por la tutela del trabajo, la protección de los débiles y la igualación de los desiguales.

Pero no era una tercera vía, una vía intermedia; era más bien (o mejor, debía o habría debido, y con mayor razón debería hoy, concebirse como) la prosecución de la primera vía; aquélla, cierto que no llana, fácil ni rectilínea que históricamente ya había conducido desde el liberalismo hacia la democracia, mediante algunas conquistas decisivas en el proceso de democratización de los Estados liberales, como la abolición de las barreras censitarias para el derecho de voto; la vía nunca definitivamente encontrada, continuamente buscada y explorada, y repetidamente modificada corrigiendo su dirección, de un único, difícil y complejo proyecto de emancipación: un proyecto, no un destino inscrito en las leyes de la historia; la primera, la única vía, aunque incierta e insegura, que se debía intentar recuperar y proseguir partiendo nuevamente desde un núcleo de valores de la tradición liberal, porque la otra, la segunda vía, que parecía girar hacia la izquierda alejándose del principio de libertad individual, juzgado y condenado sumariamente como «burgués», era en realidad un callejón sin salida que conduciría a la inversión de la utopía, es decir, a la perversión del proyecto de emancipación.

Era una vía que, pasando más allá de aquel engañoso giro, se debía intentar recorrer - más aún, trazar, excavar - con la combinación de dos estrategias. Ante todo era necesario instituir una jerarquía entre los derechos mismos de libertad de la tradición liberal mediante la atribución de un rango subordinado y vinculado por condiciones y límites al derecho de propiedad, no ya porque éste no debiera ser reconocido como un derecho individual, sino para evitar que pudiera atraer a su esfera y en el límite fagocitar las que BOBBIo llama «las cuatro grandes libertades de los modernos», inalienables e indisponibles, sustraídas a cualquier poder, sea del Estado o del mercado: la libertad personal, es decir, la inmunidad de detención arbitraria y de tortura; la libertad de conciencia y de pensamiento, que implica el derecho de manifestar las propias opiniones; la libertad de reunión, que comprende el derecho de protesta colectiva; la libertad de asociación, que permite la libre formación de partidos y 
sindicatos, y con ella la de los sujetos de la vida democrática. En segundo lugar y consecuentemente, se debía proceder a la declaración de los derechos sociales, a su reconocimiento como derechos fundamentales en igual plano que los derechos de libertad, como aquellos universales e iguales, es decir, atribuidos igualmente a todos, sobre todo para evitar que las libertades iguales de derecho continuasen siendo o se transformaran en desigualdades de hecho: de este modo los derechos sociales - al trabajo, a la educación, a la salud, a la previsión social y a la subsistencia- eran concebidos como precondiciones de la igual libertad. $\mathrm{O}$ mejor, como precondiciones para el efectivo disfrute de los derechos de libertad y, por lo tanto, también para el correcto ejercicio de los derechos políticos mismos, de los cuales los derechos fundamentales de libertad son precondiciones a su vez. ¿Qué sentido tendrían los derechos de participación política si no estuvieran garantizados los derechos a la libre manifestación del pensamiento, a la libre reunión y asociación? ¿Pero qué sentido tendría la libertad de pensamiento, de reunión, de asociación sin el derecho a la educación por un lado y a la información libre y plural por el otro? ¿Cuánto valor tienen los derechos de libertad sin un poder concreto para hacer aquello que está permitido hacer? ¿Para quién tienen valor estos derechos, sin condiciones materiales que coloquen a los individuos como tales, a todos los individuos, en condición de ser libres?

A la democracia así entendida BoBBIo la llamaba en ocasiones (como también CALAMANDREI) «democracia social», para subrayar, justamente, que el fundamento de toda la construcción residiría en la garantía de los derechos sociales. Pero quizás se debería llamar más correctamente «democracia liberalsocialista». La democracia es liberalsocialista en sus precondiciones, que son indisociablemente liberales y sociales. Es decir: el liberalsocialismo de los derechos fundamentales es la precondición de una democracia no frágil y no aparente. Esta idea de democracia, remarca BOBBIO, «nace claramente del punto de encuentro e integración recíproca de los ideales liberales y los socialistas» ${ }^{6}$.

Para concluir, querría sugerir un esquema analítico ulterior. En el liberalsocialismo (o socialismo liberal) como concepción ideal, que propone un modelo prescriptivo propio de convivencia, quizá sería apropiado distinguir dos niveles, dos grados. El primer nivel es el que he intentado delinear reconstruyendo el núcleo de la elaboración de BoBBIO sobre los derechos fundamentales. En este plano, el objetivo que el liberalsocialismo persigue es precisamente la garantía de las precondiciones sociales y liberales de la democracia a través de la instauración primero y de la preservación después del Estado constitucional de Derecho tal y como se ha desarrollado en el paradigma de las llamadas «Constituciones largas», un paradigma iniciado en la posguerra precisamente por la Constitución italiana y destinado a convertirse en dominante en la segunda mitad del siglo XX. La asunción de este modelo general de convivencia política caracteriza al que llamaré liberalsocialismo mínimo, en el sentido del mínimo indispensable para la democracia: aquel núcleo esencial de derechos de libertad y sociales que debe ser asegurado y defendido, sustrayéndolo al poder tanto del mercado como de las mayorías contingentes, para que las propias reglas de juego no sean vacia-

\footnotetext{
${ }^{6}$ Bobbio, N., 1990: «Il pensiero politico [di Calamandrei]», en Barile, P. (comp.), Piero Calamandrei. Ventidue saggi su un grande maestro, Padova: Cedam, ahora recogido en BoBBio, N., 1997: Dal fascismo alla democrazia, comp. por Bovero, M., BAlDini \& CASTOLDI, Milano (por donde cito), p. 332.
} 
das y el juego no resulte desequilibrado o incluso amañado; en resumen, para prevenir el riesgo de un nuevo régimen, quizá disfrazado bajo apariencias democráticas, pero basado en el condicionamiento material y moral (precariedad social, información manipulada y distorsionada, etc.) de la voluntad política de los ciudadanos.

En un segundo y superior nivel, el liberalsocialismo se caracteriza por la búsqueda constante, e inagotable, de la conjugación entre la máxima libertad individual y la máxima justicia social históricamente posibles en cada ocasión. El ideal regulativo de una sociedad de libres e iguales se debe saber traducir a formas específicas, cada vez más complejas y articuladas, relacionándose con el cambio de las condiciones sociales y, sobre todo, sugiere BOBBIO, «con el progreso de la capacidad del hombre de dominar la naturaleza y a los demás hombres». El crecimiento de las potencialidades humanas es ambiguo: pueden, por un lado, producir «nuevas amenazas a la libertad del individuo», y por el otro, «nuevos remedios a su indigencia» ${ }^{7}$. Los riesgos para la libertad se neutralizan mediante la creación de nuevos límites, vínculos y controles a la acción de los poderes públicos y privados; las oportunidades de satisfacción igualitaria de nuevas (y viejas) necesidades se realizan instituyendo las correspondientes obligaciones de prestación para los poderes públicos. Esto, que yo llamaría liberalsocialismo máximo, puede, y en mi opinión debería ser, el alma ideal de un partido (o movimiento) político. Un partido de izquierda, obviamente, universalista e igualitario, que pretenda desarrollar en la normal dialéctica democrática la tarea de promover el mejor balance entre las aspiraciones de justicia y libertad: combatiendo las recurrentes tendencias al deslizamiento hacia el Estado mínimo, deseado por los sostenedores del mercado máximo, generador y multiplicador de desigualdad, de discriminaciones y privilegios; pero oponiéndose al mismo tiempo y en igual medida también a los peligros de la exorbitancia de los poderes públicos en la esfera de la autodeterminación individual.

El primero, que he llamado mínimo, es el liberalsocialismo para la democracia: la realización de su programa pone las precondiciones para el desarrollo correcto del juego democrático, para la competición equitativa entre tendencias políticas diferentes y por lo tanto para la dialéctica normal entre mayorías y minorías, y entre gobierno y oposición, sobre la que se funda el ejercicio legítimo del poder. El segundo, que he llamado máximo, es el liberalsocialismo en la democracia: su programa debería ser el de un partido o movimiento político que quiere asumir un peculiar papel propio, en competición con otros dentro de la arena política democrática.

Pues bien: el primer liberalsocialismo, después de los fascismos y de los totalitarismos, debería o habría debido resultar patrimonio colectivo, compartido por todos los componentes de una sociedad democrática, y justo por ello traducido y fijado en normas constitucionales. Pero ahora la Constitución, o mejor el constitucionalismo, el paradigma del Estado de Derecho y con ellos la propia democracia, son directamente atacados, y no sólo en Italia sino en el mundo entero. Están amenazados por la globalización y por las políticas predominantes que la consienten y la fomentan; aún más, por las globalizaciones: del mercado, del miedo, de la guerra. De ello derivan

\footnotetext{
7 Bobbio, N., 1990: L'età dei diritti, Torino: Einaudi, 3. a ed. 1997, p. XV [trad. cast., con la adición de tres textos, 1993: El tiempo de los derechos, Madrid: Sistema.
} 
graves lesiones ante todo a los derechos sociales, pero también, después, a los derechos de libertad (basta pensar en el desgraciado intercambio de «libertad por seguridad»), y por lo tanto a los derechos políticos, que resultan debilitados por falta de precondiciones liberales y sociales y reducidos a merced de pulsiones demagógicas. En consecuencia, el liberalsocialismo — al menos el mínimo— no puede dejar de volver a estar de actualidad.

Espero que ahora resulte más claro: no se trata de una tercera vía. Aún menos de la tercera vía de Tony Blair. Un amigo británico me ha contado una chanza que circula hace tiempo en Inglaterra, según la cual la tercera vía de Blair sería adecuadamente presentable como la suma de una política económica sustancialmente idéntica a la de las derechas neoliberistas, y de una retórica comunitarista, que apela a un paradigma holista y orgánico. Cabría afirmar: exactamente las dos versiones del liberalismo y del socialismo que no son compatibles entre sí. En todo caso, y más allá de chanza, de la lección de BOBBio se obtienen indicaciones muy diferentes a éstas, incluso, opuestas: la tercera vía no existe; la única vía de izquierda, aquella que hoy debemos volver a recorrer, conduce a afrontar, esta vez a escala global, planetaria, el problema de la garantía conjunta de los derechos fundamentales de matriz liberal y socialista. De nuevo y todavía, justicia y libertad.

(Trad. de Álvaro Núñez Vaquero) 